\title{
Associations of statins and antiretroviral drugs with the onset of type 2 diabetes among HIV-1-infected patients
}

\author{
Vincenzo Spagnuolo ${ }^{1,2^{*}}$ D, Laura Galli ${ }^{1}$, Andrea Poli ${ }^{2}$, Stefania Salpietro ${ }^{1}$, Nicola Gianotti ${ }^{1}$, Piermarco Piatti ${ }^{3}$, \\ Francesca Cossarini ${ }^{1}$, Concetta Vinci ${ }^{1}$, Elisabetta Carini ${ }^{1}$, Adriano Lazzarin ${ }^{1,2}$ and Antonella Castagna ${ }^{1,2}$
}

\begin{abstract}
Background: Statin use is associated with a modest increase in the incidence of type 2 diabetes mellitus (DM) among the general population. However, HIV-infected patients have a higher risk of developing DM, and it is unclear whether statins have a diabetogenic effect in these patients. Therefore, we investigated the associations of statin use and exposure to antiretroviral drugs with type $2 \mathrm{DM}$ onset in a cohort of HIV-infected patients.

Methods: This retrospective, controlled, cohort study identified HIV-1-infected patients who did not have DM and were not receiving statins at their antiretroviral treatment (ART) initiation. Follow-up was accrued from ART initiation to the earliest instance of a DM diagnosis, loss to follow-up, death, or last available visit. The incidence of DM was estimated according to statin use, which was adjusted for periods without statin treatment. The Fine-Gray competing risk model was used in the multivariate analysis to identify risk factors for developing DM.

Results: The analyses evaluated 6,195 patients followed for 9.8 years (interquartile range: 4.3-16.3 years). During 64,149 person-years of follow-up (PYFU), 235 patients developed DM (crude incidence: 3.66 [95\%Cl: 3.20-4.13] per 1,000 PYFU), and 917 (14\%) patients used statins. After adjusting for potential confounders, statin use was associated with a non-significant increase in the risk of DM (AHR: 1.21, 95\% Cl: $0.71-2.07 ; P=0.47$ ). DM was more likely among patients who were ever treated with stavudine, and less likely among those ever treated using emtricitabine, tenofovir, abacavir, efavirenz, nevirapine, atazanavir or darunavir.

Conclusions: A higher risk of diabetes mellitus was not associated with statin treatment but with traditional risk factors and stavudine use while a reduced risk of DM was associated with the use of emtricitabine, tenofovir, abacavir, efavirenz, nevirapine, atazanavir or darunavir.
\end{abstract}

Keywords: Diabetes, Statins, HIV, Antiretrovirals drugs, Risk factors, Cohort study

\section{Background}

Hypercholesterolemia is common among HIV-infected patients who are receiving antiretroviral therapy (ART) [1] and can contribute to the increased risk of cardiovascular disease in this population [2,3]. Therefore, 3-hydroxy-3methylglutaryl-coenzymeA (HMG-CoA) reductase inhibitors (statins) are recommended [4] and extensively prescribed to treat hypercholesterolemia and to prevent

\footnotetext{
* Correspondence: spagnuolo.vincenzo@hsr.it

${ }^{1}$ Department of Infectious Diseases, San Raffaele Scientific Institute, via Stamira d'Ancona 20, 20127 Milan, Italy

${ }^{2}$ Università Vita-Salute San Raffaele, Milan, Italy

Full list of author information is available at the end of the article
}

cardiovascular events among HIV-infected patients. In additional to their cholesterol-lowering properties, statins have recently been associated with reductions in overall mortality [5-7], the risk of non-AIDS malignancies [7, 8] and the risk of AIDS-defining malignancies $[8,9]$ among HIV-infected patients.

In contrast, concerns have recently been raised regarding glucose metabolism impairment among statin users, with different studies in the general population revealing a possible association between statin use and the risk of incident type 2 diabetes mellitus (DM) $[10,11]$, as well as a dose-related effect [12]. Although the mechanisms underlying this increased risk 
of incident DM are not fully understood, Mendelian randomization studies [13] suggest that they are related, at least in part, to reduced HMG-CoA reductase activity [14]. Therefore, the possible diabetogenic effect of statins may be particularly relevant among HIVpositive patients, who have a higher risk of developing DM, compared to the general population [15].

Unfortunately, there are few studies regarding statin use and incident DM among HIV-infected patients, and these studies have reported not univocal results. For example, a randomized study [16] of 72 patients reported that rosuvastatin use was associated with increased insulin resistance but not with a clinical diagnosis of DM and a recent italian study did not observe any association between statins use and DM risk [17]. In contrast, the HOPS cohort study [18] found a slightly increased risk of incident DM among patients who were treated using statins. Therefore, the present study aimed to evaluate the associations of statin use and exposure to antiretroviral drugs with the onset of type $2 \mathrm{DM}$ in a large cohort of HIV-infected patients.

\section{Methods}

This retrospective observational study was approved by the ethics committee of the San Raffaele Scientific Institute, and examined patient data from the Infectious Diseases Department database at the San Raffaele Hospital (IDD-HSR). This observational database collects demographic, clinical, therapeutic, and laboratory data from adult patients who are receiving primary inpatient or outpatient care for HIV infection at the Infectious Diseases Department of the San Raffaele Scientific Institute (Milan, Italy). At their first visit to the clinic, the patients provide written informed consent for scientific analysis of their clinical and laboratory data. Information regarding the prescribed antiretroviral and concomitant drugs (type, dosage, and dates of start and stop) are prospectively recorded at each visit by the treating physician, and these data are subsequently checked by skilled data managers. However, patient adherence to the prescribed drugs is not routinely assessed.

In the present study, we included adults who were infected with HIV-1 and subsequently started ART between January 1991 and November 2014. These patients were not using statins, had not been diagnosed with type $2 \mathrm{DM}$ at the start of ART, and had undergone at least one test to determine their fasting glucose and lipid levels after starting the ART (i.e., one follow-up examination in addition to that of baseline). Details of the patients' selection process is illustrated in the Additional file 1: Figure S1.

We diagnosed DM according to the American Diabetes Association criteria [19], based on two consecutive fasting plasma glucose levels of $\geq 126 \mathrm{mg} / \mathrm{dL}$, or a 2 -h plasma glucose level $\geq 200 \mathrm{mg} / \mathrm{dL}$ during an oral glucose tolerance test, or two consecutive fasting glycated hemoglobin levels of $\geq 48 \mathrm{mmol} / \mathrm{mol}$, or a prescription for any antidiabetic medication [the median (IQR) number of fasting glucose determinations per patient was 29 (13-50)]. An expert physician (VS) and a diabetologist (PP) reviewed all diagnoses to verify the data's plausibility and completeness before the analyses. We excluded patients with a diagnosis of type $2 \mathrm{DM}$ before the initiation of ART (prevalent cases).

In the present study, all statin treatments were started after the initiation of ART, and preceded the diagnosis of DM (if applicable). Patients were required to receive a statin for at least 30 days to be considered a statin user. To evaluate the effect of statin dose on the incidence of $\mathrm{DM}$, we considered the following dose categories [11]: high dose (rosuvastatin at $\geq 40 \mathrm{mg}$ or atorvastatin at $\geq 80 \mathrm{mg}$ ), moderate dose (rosuvastatin at $10-40 \mathrm{mg}$, atorvastatin at $20-80 \mathrm{mg}$, or simvastatin at $\geq 80 \mathrm{mg}$ ), and low dose (rosuvastatin at $<10 \mathrm{mg}$, atorvastatin at $<20 \mathrm{mg}$, simvastatin at $<80 \mathrm{mg}$, or fluvastatin and pravastatin at any dose); patients were categorized according to the highest dose category recorded during follow-up.

Follow-up was counted from the date of starting ART (baseline) to the earliest instance of a type 2 DM diagnosis, death, loss to follow-up, or last available visit.

Results were reported as median (interquartile range [IQR]) or frequency (\%), as appropriate. The baseline characteristics of HIV-infected patients according to statin use were compared using the chi-square test for categorical variables and the Wilcoxon rank-sum test for continuous variables. Crude rates of incident type $2 \mathrm{DM}$ were reported as events per 1,000 person-years with the exact 95\% Poisson confidence intervals (CIs) among the entire sample, non-statin users, and statin users (the calculation for statin users accounted for their periods of non-use) [20].

The effect of death as an event competing with the onset of type 2 DM was modeled using the Fine-Gray model [21], and factors that were associated with the onset of type $2 \mathrm{DM}$ were identified using subhazard ratios (a measure of relative risk that considers death). No major violations of the proportional-hazards assumption were detected using the interactions terms of the predictors as a function of time. The multivariate model (Model 1) included characteristics with a $p$-value of $\leq .20$ in the univariate analyses or factors that are commonly associated with DM (e.g., smoking or hepatitis $C$ virus [HCV] co-infection) in addition to the calendar year of ART initiation. We classified patients as smokers if they had smoked at least once, and patients who were anti$\mathrm{HCV}$-positive based on at least one positive HCVantibody test result. Patients were categorized according to the highest BMI recorded during the follow-up. Race 
was not included in the multivariate models, as almost all patients (with or without DM) were white. All ART drugs that were used by at least $25 \%$ of the patients and darunavir (used by $23 \%$ ) were also included in the multivariate models (regardless of their $p$-value in the univariate analyses) to investigate the association between these drugs and DM occurrence. The use of ritonavir included both full and boosting doses. Statin use was considered as a time-updated variable: patients who had a history of statin prescriptions during the follow-up

Table 1 Patients characteristics according to occurrence of type 2 diabetes

\begin{tabular}{|c|c|c|c|}
\hline Characteristics & Type 2 diabetes $(n=235)$ & No type 2 diabetes $(n=5960)$ & $p$-value \\
\hline Age (years), median (IQR) & $40.3(35.6-50.0)$ & $35.3(30.2-41.6)$ & $<0.001^{a}$ \\
\hline Males, $n$ (\%) & $201(86 \%)$ & $4627(78 \%)$ & $0.002^{b}$ \\
\hline White Race, $n(\%)$ & $224(95 \%)$ & $5542(93 \%)$ & $0.16^{\mathrm{b}}$ \\
\hline Smoke, $n(\%)$ & & & $0.96^{\mathrm{b}}$ \\
\hline Current/ex-smoker & $99(42 \%)$ & $2384(40 \%)$ & \\
\hline Never & $75(32 \%)$ & $2086(35 \%)$ & \\
\hline Unknown & $61(26 \%)$ & $1490(25 \%)$ & \\
\hline Body Mass Index, n (\%) & & & $<0.001^{\mathrm{b}}$ \\
\hline Normal (<25 kg/m2) & $83(35 \%)$ & $2463(41 \%)$ & \\
\hline Overweight (25-29.9 kg/m2) & $69(29 \%)$ & $1425(24 \%)$ & \\
\hline Obese ( $\geq 30$ kg/m2) & $34(15 \%)$ & $355(6 \%)$ & \\
\hline Unknown & $49(21 \%)$ & $1717(29 \%)$ & \\
\hline HIV risk factor, $n(\%)$ & & & $0.015^{\mathrm{b}}$ \\
\hline IVDU & $46(20 \%)$ & $1134(19 \%)$ & \\
\hline MSM & $54(23 \%)$ & $1893(32 \%)$ & \\
\hline Heterosexual & $49(21 \%)$ & $1225(21 \%)$ & \\
\hline Other/Unknown & $86(37 \%)$ & $1708(29 \%)$ & \\
\hline Ab-anti HCV, $n(\%)$ & & & $0.014^{b}$ \\
\hline Positive & $83(35 \%)$ & $1617(27 \%)$ & \\
\hline Negative & $135(58 \%)$ & $3729(63 \%)$ & \\
\hline Unknown & $17(7 \%)$ & $613(10 \%)$ & \\
\hline HBsAg, $n(\%)$ & & & $0.004^{b}$ \\
\hline Positive & $21(9 \%)$ & $323(5 \%)$ & \\
\hline Negative & $197(84 \%)$ & $4853(82 \%)$ & \\
\hline Unknown & $17(7 \%)$ & $784(13 \%)$ & \\
\hline Years since first HIV-positive test, median (IQR) & $19.0(14.4-25.6)$ & $14.4(7.7-20.9)$ & $<0.001^{\mathrm{a}}$ \\
\hline AIDS diagnosis before ART, median (IQR) & $29(12 \%)$ & $599(10 \%)$ & $0.27^{\mathrm{b}}$ \\
\hline Nadir CD4 cell count before ART (cells/uL), median (IQR) & $231(91-395)$ & $285(165-408)$ & $0.019^{\mathrm{a}}$ \\
\hline Baseline Total Cholesterol (mg/dL), median (IQR) & 153 (127-198) (available in 126 pts) & 157 (132-183) (available in 2271 pts) & $0.92^{\mathrm{a}}$ \\
\hline Baseline HDL-cholesterol (mg/dL), median (IQR) & 35 (31-40) (available in 6 pts) & 38 (32-45) (available in 1056 pts) & $0.53^{\mathrm{a}}$ \\
\hline Baseline LDL-cholesterol (mg/dL), median (IQR) & 98 (84-114) (available in 4 pts) & 100 (80-121) (available in 985 pts) & $0.87^{\mathrm{a}}$ \\
\hline Baseline Fasting Glucose (mg/dL), median (IQR) & 96 (85-106) (available in 51 pts) & 85 (79-92) (available in 2626 pts) & $<0.001^{\mathrm{a}}$ \\
\hline Baseline Triglycerides (mg/dL), c & 144 (116-206) (available in 43 pts) & 103 (75-150) (available in 2324 pts) & $<0.001^{\mathrm{a}}$ \\
\hline Baseline CD4 cell count (cells/ $\mu \mathrm{L})$, median (IQR) & 240 (99-422) (available in 126 pts) & 307 (177-443) (available in 3557 pts) & $0.018^{\mathrm{a}}$ \\
\hline Baseline HIV-RNA ( $\log _{10}$ copies/ml), median (IQR) & 4.78 (4.17-5.31) (available in 76 pts) & 4.74 (4.16-5.20) (available in 2929 pts) & $0.65^{\mathrm{a}}$ \\
\hline Baseline haemoglobin (mg/dl), median (IQR) & 13.7 (11.9-15.1) (available in 61 pts) & 14.0 (12.7-14.9) (available in 2883 pts) & $0.63^{\mathrm{a}}$ \\
\hline Baseline creatinine (mg/dl), median (IQR) & 0.87 (0.72-0.96) (available in 34 pts) & 0.82 (0.71-0.93) (available in 2205 pts) & $0.70^{\mathrm{a}}$ \\
\hline
\end{tabular}

Baseline: date of ART initiation; if not indicated the characteristic is intended at the censoring date

${ }^{a}$ by Wilcoxon rank sum test

${ }^{\mathrm{b}}$ by Chi-square or Fisher exact test, as appropriate 
were alternatively considered over time as either nonstatin users or statin users depending on whether they were receiving the treatment or not. The other timeupdated covariates were age, CD4+, HIV RNA, hemoglobin levels, and fasting levels of glucose and triglycerides. A second multivariate model accounted for the effect of an additional risk factor (Model 2) including high-density lipoprotein (HDL)-cholesterol (time-updated variable), as this factor is independently associated with new-onset DM [22].

Table 2 Patients characteristics according to statins use

\begin{tabular}{|c|c|c|c|}
\hline Characteristics & Statin users $(n=917)$ & Non-Statin users $(n=5278)$ & $p$-value \\
\hline Age (years), median (IQR) & $38.6(32.3-45.9)$ & $35.1(30.2-41.1)$ & $<0.001^{\mathrm{a}}$ \\
\hline Males, $n$ (\%) & $722(79 \%)$ & $4106(78 \%)$ & $0.55^{\mathrm{b}}$ \\
\hline White Race, $n(\%)$ & $881(96 \%)$ & 4909 (93\%) & $0.09^{b}$ \\
\hline Smoke, $n(\%)$ & & & $<0.001^{b}$ \\
\hline Current/ex-smoker & $395(43 \%)$ & $2088(39 \%)$ & \\
\hline Never & $271(30 \%)$ & $1870(38 \%)$ & \\
\hline Unknown & $251(27 \%)$ & $1320(23 \%)$ & \\
\hline Body Mass Index, $n$ (\%) & & & $<0.001^{b}$ \\
\hline Normal (<25 kg/m2) & $409(45 \%)$ & $2137(41 \%)$ & \\
\hline Overweight (25-29.9kg/m2) & $323(35 \%)$ & $1171(22 \%)$ & \\
\hline Obese ( $\geq 30$ kg/m2) & $100(11 \%)$ & $289(5 \%)$ & \\
\hline Unknown & $85(9 \%)$ & $1681(32 \%)$ & \\
\hline HIV risk factor, $n(\%)$ & & & $<0.001^{b}$ \\
\hline IVDU & $73(8 \%)$ & 1107 (21\%) & \\
\hline MSM & $246(27 \%)$ & $1028(20 \%)$ & \\
\hline Heterosexual & $352(38 \%)$ & $1595(30 \%)$ & \\
\hline Other/Unknown & $246(27 \%)$ & $1548(29 \%)$ & \\
\hline Ab-anti HCV, $n(\%)$ & & & $<0.001^{b}$ \\
\hline Positive & $136(15 \%)$ & $1564(30 \%)$ & \\
\hline Negative & $721(77 \%)$ & $3143(60 \%)$ & \\
\hline Unknown & $60(7 \%)$ & $570(11 \%)$ & \\
\hline HBsAg, $n(\%)$ & & & $0.001^{b}$ \\
\hline Positive & $42(5 \%)$ & $302(6 \%)$ & \\
\hline Negative & $787(86 \%)$ & $4263(81 \%)$ & \\
\hline Unknown & $88(10 \%)$ & $713(14 \%)$ & \\
\hline Years since first HIV-positive test, median (IQR) & $18.0(11.5-22.8)$ & $14.1(7.4-20.7)$ & $<0.001^{\mathrm{a}}$ \\
\hline AIDS diagnosis before ART, median (IQR) & $96(11 \%)$ & $532(10 \%)$ & $0.72^{b}$ \\
\hline Nadir CD4 cell count before ART (cells/mL), median (IQR) & $285(177-398)$ & $283(160-412)$ & $0.99^{\mathrm{a}}$ \\
\hline Baseline Total Cholesterol (mg/dL), median(IQR) & 183 (154-207) (available in 301 pts) & 154 (131-179) (available in 2013 pts) & $<0.001^{a}$ \\
\hline Baseline HDL-cholesterol (mg/dL), median(IQR) & 38 (32-44) (available in 123 pts) & 38 (32-45) (available in 939 pts) & $0.56^{\mathrm{a}}$ \\
\hline Baseline LDL-cholesterol (mg/dL), median (IQR) & 124 (102-150) (available in 111 pts) & 98 (79-117) (available in 878 pts) & $<0.001^{\mathrm{a}}$ \\
\hline Baseline Fasting Glucose (mg/dL), median (IQR) & 88 (81-95) (available in 375 pts) & 85 (79-92) (available in 2302 pts) & $<0.001^{\mathrm{a}}$ \\
\hline Baseline Triglycerides (mg/dL), median (IQR) & 110 (82-170) (available in 318 pts) & 102 (75-148) (available in 2049 pts) & $<0.001^{a}$ \\
\hline Baseline CD4 cell count (cells/ $\mu \mathrm{L}$ ), median (IQR) & 300 (186-433) (available in 564 pts) & 307 (171-444) (available in 3119 pts) & $0.75^{\mathrm{a}}$ \\
\hline Baseline HIV-RNA ( $\log _{10}$ copies/ml), median(IQR) & 4.72 (4.18-5.15) (available in 421 pts) & 4.74 (4.15-5.20) (available in 2584 pts) & $0.85^{a}$ \\
\hline Baseline hemoglobin (mg/dl), median (IQR) & 13.9 (12.8-14.8) (available in 403 pts) & 14 (12.7-14.9) (available in 2541 pts) & $0.72^{\mathrm{a}}$ \\
\hline Baseline creatinine (mg/dl), median (IQR) & 0.85 (0.75-0.95) (available in 287 pts) & 0.81 (0.71-0.93) (available in 1952 pts) & $0.017^{\mathrm{a}}$ \\
\hline
\end{tabular}

Baseline: date of ART initiation; if not indicated the characteristic is intended at the censoring date

${ }^{a}$ by Wilcoxon rank sum test

${ }^{\mathrm{b}}$ by Chi-square or Fisher exact test, as appropriate 
All statistical tests were two-sided at the 5\% level and were performed using SAS software (version 9.2; SAS Institute, Cary, NC).

\section{Results}

We evaluated data from 6,195 patients, who included $4,828(78 \%)$ men. The median age at the end of followup was 47.2 years (IQR: 40.6-52.7 years), the median time since the first HIV-positive result was 15 years (IQR: 8-21 years), and the median duration of ART was 10 years (IQR: 4-16 years). Approximately $27 \%$ of the patients exhibited HCV-positive serology results, $6 \%$ of the patients had a reactive $\mathrm{HBV}$ surface antigen. The median nadir CD4+ cell count was 283 cells/ $\mu \mathrm{L}$ (IQR: $162-408$ cells $/ \mu \mathrm{L}), 10 \%$ of the patients were diagnosed with AIDS before initiating ART, 28\% of the patients were smokers, and the median BMI was $23.0 \mathrm{~kg} / \mathrm{m}^{2}$ (IQR: $21.1-25.7 \mathrm{~kg} / \mathrm{m}^{2}$ ). The median baseline laboratory results were total cholesterol levels of $157 \mathrm{mg} / \mathrm{dL}$ (IQR: 132-184 mg/dL), low-density lipoprotein (LDL) cholesterol levels of $100 \mathrm{mg} / \mathrm{dL}$ (IQR: $80-121 \mathrm{mg} / \mathrm{dL}$ ), HDLcholesterol levels of $38 \mathrm{mg} / \mathrm{dL}$ (IQR: $32-45 \mathrm{mg} / \mathrm{dL}$ ), triglyceride levels of $104 \mathrm{mg} / \mathrm{dL}$ (IQR: 75-152 mg/dL), fasting plasma glucose levels of $85 \mathrm{mg} / \mathrm{dL}$ (IQR: 79$92 \mathrm{mg} / \mathrm{dL}$ ), CD4+ cell counts of 307 cells/ $\mu \mathrm{L}$ (IQR: 174442 cells $/ \mu \mathrm{L}$ ), and $\log _{10}$ HIV RNA levels of 4.74 (IQR: 4.16-5.20). During the follow-up, 97\% of the patients used nucleoside reverse transcriptase inhibitors (NRTIs), $79 \%$ of the patients used protease inhibitors (PIs), $61 \%$ of the patients used non-nucleoside reverse transcriptase inhibitors, $12 \%$ of the patients used integrase strand transfer inhibitors, and $9 \%$ of the patients used entry inhibitors.

During 64,149 person-years of follow-up, 235 patients developed DM, which corresponded to a crude incidence rate of 3.66 per 1,000 person-years of follow-up (95\% CI: $3.20-4.13$ per 1,000 person-years of follow-up). The patients' characteristics according to DM status are reported in Table 1. Patients with new-onset DM were more likely to be older, male, overweight or obese, coinfected with $\mathrm{HCV}$ or $\mathrm{HBV}$, exhibit prolonged HIV infection, and have a lower CD4+ cell count nadir. When we analyzed the exposures to ART drugs according to the occurrence of DM (Additional file 2: Table S1), we observed that patients with DM were more likely to be exposed to "first-generation" NRTIs (e.g., zidovudine, stavudine, didanosine and lamivudine) or PIs (indinavir, nelfinavir, and saquinavir), compared to patients without DM.

In total, 917 patients used statins during the follow-up, and their characteristics are listed in Table 2. We observed a significant difference in the risk factors for cardiovascular disease between statin users and non-users, and statin users also exhibited higher baseline glucose levels, a longer duration of HIV infection and a longer duration of ART. The median calendar year of statin initiation was 2011 (2009-2012) and the median duration of statin therapy was 37.3 months (IQR: 20.359.2 months), which accounted for $25 \%$ of the total follow-up among the statin users. The most commonly prescribed statins were rosuvastatin $(n=766,83.5 \%)$ and atorvastatin $(n=95,10.4 \%)$.

The incidence of DM according to statin use is reported in Table 3. Patients who developed DM exhibited a similar duration of statin treatment, compared to patients who did not develop DM (37.7 months [IQR: 20.3-60.1 months] vs. 32.7 months [IQR: 14.844.2 months], respectively; $P=0.13)$. High-dose statin therapy was used by $2 / 23(8.7 \%)$ of the patients who developed DM, compared to by $21 / 894(2.3 \%)$ of the patients who did not developed DM $(P=0.11)$.

The results from the univariate analyses of DM risk by use of the Fine-Gray models are reported in Table 4.

In the multivariate analysis (Model 1, Table 5), we observed that a lower risk of DM was associated with higher values of CD4+ cell count and exposure to abacavir, emtricitabine, tenofovir, efavirenz, nevirapine, atazanavir, darunavir. In contrast, a higher risk of DM was associated with the use of stavudine, older age, obesity, detectable HIV RNA levels, higher current triglyceride levels, higher current fasting glucose levels, higher current hemoglobin levels and shorter ART duration. Statin use was associated with a non-significant increase in the risk of DM (adjusted hazard ratio [AHR] 1.21, 95\% CI: 0.71-2.07; $P=0.47$ ). The statin-dependent risk of developing DM was not significantly affected by the

Table 3 Incidence of type 2 diabetes according to statin use

\begin{tabular}{llll}
\hline Characteristic & Statins users $(n=917)$ & Non-Statin users $(n=5278)$ & $p$-value \\
\hline Diagnoses of type 2 diabetes & $23(2.5 \%)$ & $212(4.0 \%)$ & $0.025^{\text {a }}$ \\
$\begin{array}{l}\text { Person-years of follow-up (PYFU) } \\
\text { median follow-up (IQR), years }\end{array}$ & $1272015.4(8.9-18.1)$ & $514298.9(3.8-15.5)$ & $<0.001^{\text {b }}$ \\
Incidence rate of type 2 diabetes (95\%Cl) per 1000-PYFU & $7.1(4.2-10.1)^{\mathrm{c}}$ & $3.5(3.0-4.0)$ & $0.041^{\text {d }}$ \\
\hline
\end{tabular}

${ }^{a}$ by Chi-square test

${ }^{\mathrm{b}}$ by Wilcoxon rank-sum test

${ }^{c}$ Incidence rate of statin users was calculated using only PYFU effectively spent on statin treatment while their untreated PYFU was added to PYFU of non-statin users

${ }^{d}$ by univariate Fine-Gray regression model $[\mathrm{HR}=1.58(95 \% \mathrm{Cl}: 1.02-2.46)]$ 
Table 4 Univariate analyses on the risk for DM occurrence by Fine and Gray regression models

\begin{tabular}{|c|c|c|c|}
\hline Characteristics & $\mathrm{HR}$ & $95 \% \mathrm{Cl}$ & $p$-value \\
\hline$\overline{\text { Age (per 5-years higher) }}{ }^{a}$ & 1.477 & $1.406-1.551$ & $<0.001$ \\
\hline Gender (male vs female) & 2.037 & $1.400-2.963$ & $<0.001$ \\
\hline Smoking & & & 0.28 \\
\hline Current/ex-smoker vs never & 0.764 & $0.545-1.070$ & 0.12 \\
\hline unknown vs never & 0.904 & $0.572-1.429$ & 0.67 \\
\hline BMI & & & $<0.001$ \\
\hline$\geq 25<30$ vs $<25 \mathrm{~kg} / \mathrm{m}^{2}$ & 1.401 & $1.001-1.959$ & 0.049 \\
\hline$>30$ vs $<25 \mathrm{~kg} / \mathrm{m}^{2}$ & 2.706 & $1.768-4.143$ & $<0.001$ \\
\hline Unknown vs $<25 \mathrm{~kg} / \mathrm{m}^{2}$ & 1.574 & $1.085-2.282$ & 0.017 \\
\hline HIV risk factor & & & $<0.001$ \\
\hline IVDU vs heterosexual & 0.785 & $0.515-1.197$ & 0.26 \\
\hline MSM vs heterosexual & 0.932 & $0.622-1.396$ & 0.73 \\
\hline Other/unknown vs heterosexual & 1.646 & $1.138-2.380$ & 0.008 \\
\hline Ab-anti HCV & & & 0.55 \\
\hline Positive vs negative & 0.991 & $0.744-1.320$ & 0.95 \\
\hline Unknown vs negative & 1.350 & $0.775-2.351$ & 0.29 \\
\hline $\mathrm{HbsAg}$ & & & 0.14 \\
\hline Positive vs negative & 1.608 & $0.998-2.593$ & 0.051 \\
\hline Unknown vs negative & 1.169 & $0.683-2.003$ & 0.57 \\
\hline Years since first HIV positive test (per 5-years longer) & 0.847 & $0.759-0.946$ & 0.003 \\
\hline Nadir CD4+ cell count before ART (per 100-cells/ $\mu \mathrm{L}$ higher) & 0.889 & $0.803-0.984$ & 0.023 \\
\hline AIDS diagnosis before ART (yes vs no) & 1.273 & $0.841-1.929$ & 0.25 \\
\hline Current CD4+ (per 100-cells/ $\mu$ L higher) ${ }^{a}$ & 0.950 & $0.893-1.010$ & 0.10 \\
\hline Current HIV-RNA (per $\log 10$ copies/ml) ${ }^{a}$ & 1.261 & $1.113-1.428$ & $<0.001$ \\
\hline \multicolumn{4}{|l|}{ Current HIV-RNA ${ }^{a}$} \\
\hline$\geq 50$ vs $<50$ copies $/ \mathrm{ml}$ & 1.521 & $1.101-2.101$ & 0.011 \\
\hline Current total cholesterol (per 50-mg/dL higher) ${ }^{a}$ & 1.027 & $0.834-1.265$ & 0.80 \\
\hline Current HDL-cholesterol (per 5-mg/dL higher) ${ }^{a}$ & 0.906 & $0.822-0.999$ & 0.047 \\
\hline Current LDL-cholesterol (per 10-mg/dL higher) ${ }^{a}$ & 1.031 & $0.951-1.117$ & 0.46 \\
\hline Current triglycerides (per 50-mg/dL higher) ${ }^{a}$ & 1.061 & $1.047-1.076$ & $<0.001$ \\
\hline Current haemoglobin (per 5-g/dl higher) ${ }^{a}$ & 1.746 & $1.020-2.988$ & 0.042 \\
\hline Current fasting glucose (per 10-mg/dL higher) ${ }^{\text {a }}$ & 1.159 & $1.136-1.184$ & $<0.001$ \\
\hline Current HOMA-IR (per 1-unit higher) ${ }^{a}$ & 1.059 & $1.038-1.080$ & $<0.001$ \\
\hline Current FIB-4 (per 0.5-unit higher) ${ }^{a}$ & 1.003 & $1.001-1.006$ & 0.02 \\
\hline Current Framingham 10-year CVD risk (per 5\% higher) ${ }^{\text {a }}$ & 1.188 & $1.117-1.263$ & $<0.001$ \\
\hline Use of statins (yes vs no) ${ }^{a}$ & 1.583 & $1.019-2.457$ & 0.041 \\
\hline Calendar year of ART start (per 3-years increase) & 1.133 & $1.047-1.227$ & 0.002 \\
\hline Ever use of lamivudine (yes vs no) & 0.374 & $0.254-0.550$ & $<0.001$ \\
\hline Ever use of abacavir (yes vs no) & 0.516 & $0.393-0.677$ & $<0.001$ \\
\hline Ever use of emtricitabine (yes vs no) & 0.163 & $0.119-0.225$ & $<0.001$ \\
\hline Ever use of tenofovir (yes vs no) & 0.148 & $0.112-0.195$ & $<0.001$ \\
\hline Ever use of stavudine (yes vs no) & 0.631 & $0.482-0.827$ & 0.001 \\
\hline Ever use of zidovudine (yes vs no) & 0.834 & $0.594-1.172$ & 0.30 \\
\hline Ever use of didanosine (yes vs no) & 0.453 & $0.345-0.595$ & $<0.001$ \\
\hline
\end{tabular}


Table 4 Univariate analyses on the risk for DM occurrence by Fine and Gray regression models (Continued)

\begin{tabular}{llll}
\hline Ever use of efavirenz (yes vs no) & 0.523 & $0.394-0.695$ & $0.325-0.597$ \\
Ever use of nevirapine (yes vs no) & 0.440 & $0.227-0.420$ & $<0.001$ \\
Ever use of ritonavir (yes vs no) & 0.309 & $0.442-0.777$ & $<0.001$ \\
Ever use of saquinavir (yes vs no) & 0.586 & $0.236-0.439$ & $<.001$ \\
Ever use of lopinavir (yes vs no) & 0.322 & $0.201-0.376$ & $<0.001$ \\
Ever use of atazanavir (yes vs no) & 0.275 & $0.110-0.301$ & $<0.001$ \\
Ever use of darunavir (yes vs no) & 0.182 & $<0.001$ \\
\hline
\end{tabular}

Abbreviations: $\mathrm{HR}$, hazard ratio; $95 \% \mathrm{Cl}, 95 \%$ confidence interval of the hazard ratio; $\mathrm{NE}$, not evaluated due to the limited number of patients treated with this drug ${ }^{\text {a }}$ Time-updated covariate

additional inclusion of HDL-cholesterol levels (Model 2, AHR 1.58, 95\% CI: 0.90-2.78; $P=0.11)$.

\section{Discussion}

In the present study, we found that statin use was associated with a non-significant increase in the risk of DM occurrence among HIV-infected patients who were receiving ART. Furthermore, this increased risk became statistically significant when we considered the use of only high-dose statins. In this context, other studies have reported a dose-related diabetogenic effect for statins in the general population [12] which is probably associated to the degree of inhibition of HMG-CoA reductase activity [13]. However, there are no clear data regarding the association between statin use and DM occurrence among HIV-infected patients. For example, recent results from the randomized SATURN-HIV trial [16] revealed that the use of rosuvastatin $(10 \mathrm{mg}$ daily for 96 weeks) was associated with increased insulin resistance and poorer homeostatic model assessment of insulin resistance outcomes, but not with a clinical diagnosis of DM, among $72 \mathrm{HIV}$-infected patients. In line with our findings, the study by Calza et al. [17] evaluated a cohort of 3170 HIV-positive patients with a median follow-up of 5.2 years and concluded that statin use was not associated with the occurrence of DM [hazard ratio of 1.09 per year of statin exposure (95\% confidence interval $0.7-$ $1.49 ; P=0.067)]$. In contrast, a study of the HOPS cohort [18] reported a $14 \%$ increase in the incidence of DM for each year of statin use, although the authors did not specifically analyze the association between statin dose and DM occurrence. However, as the cardiovascular benefits of high-dose statin use outweigh the potential risk of developing DM [23], it may be advisable to regularly monitor for changes blood glucose and glycated hemoglobin levels in patients who are receiving high-dose statins and have a high risk of developing DM.

In the present study, DM occurrence was also related to classic risk factors for type $2 \mathrm{DM}$ among HIV-infected patients, such as older age, obesity, higher plasma levels of triglycerides and glucose $[15,22,24-26]$, and $\mathrm{HCV}$ co-infection [27, 28]. Moreover, we found that stavudine use was associated with DM occurrence. In this context, the deleterious effects of stavudine on glucose metabolism have already been described, [22, 29] and these effects appear to be secondary to mitochondrial toxicity and the occurrence of lipoatrophy, which are both related to DM occurrence [30, 31].

Interestingly we observed that a reduced risk of DM was associated with the use of abacavir, emtricitabine, tenofovir, efavirenz, nevirapine, atazanavir and darunavir. Previous studies have reported, albeit not consistently, that treatment using first-generation NRTIs or PIs may increase the risk of DM occurrence $[22,24-26,29,32]$, although there are very little data regarding the effect of more recently approved ART drugs on glucose metabolism. Nevertheless, the drugs that were associated with a reduced risk of DM in the present study are not clearly associated with ART-related risk factors for DM, such as severe mitochondrial toxicity, lipoatrophy, or lipodystrophy. Therefore, it is possible that these drugs had a relatively limited effect on glucose metabolism, compared to first-generation PIs and NRTIs [33-38].

The present study included several limitations that warrant consideration. First, the retrospective design limited the control over the previously collected data and doesn't exclude that some residual confounding may still exists although we are confident that the major confounders were considered. Second, the assessment of the potential relationship between statin dose and incident DM provide limited evidence of this association given the limited number of patients and, for this reason, this analysis is to be intended as exploratory.

Third, it is possible that we have overestimated the effect of statins on DM occurrence, as we considered patients as statin users based on their treatment history alone, and did not consider any possibility of noncompliance with treatment. Finally, we did not have sufficient statistical power to examine the effect of different type of statins on incident DM.

Nevertheless, the present study also included several important strengths. First, we followed-up patients on a 
Table 5 Multivariate analysis on the risk for DM occurrence by Fine and Gray regression model (model 1; the model included 186 DM diagnoses)

\begin{tabular}{|c|c|c|c|}
\hline Characteristics & AHR & $95 \% \mathrm{Cl}$ & $p$-value \\
\hline Age (per 5-years older) & 1.36 & $1.26-1.46$ & $<0.0001$ \\
\hline Gender (male vs female) & 1.08 & $0.66-1.76$ & 0.771 \\
\hline \multicolumn{4}{|l|}{ Smoking } \\
\hline Current/ex-smoker vs never & 1.16 & $0.79-1.71$ & 0.439 \\
\hline Unknown vs never & 0.48 & $0.24-0.98$ & 0.044 \\
\hline \multicolumn{4}{|l|}{ BMI } \\
\hline$\geq 25<30 \mathrm{vs}<25 \mathrm{~kg} / \mathrm{m}^{2}$ & 1.07 & $0.71-1.60$ & 0.761 \\
\hline$>30$ vs $<25 \mathrm{~kg} / \mathrm{m}^{2}$ & 2.43 & $1.34-4.40$ & 0.003 \\
\hline unknown vs $<25 \mathrm{~kg} / \mathrm{m}^{2}$ & 1.02 & $0.57-1.82$ & 0.954 \\
\hline \multicolumn{4}{|l|}{ HIV risk factor } \\
\hline IVDU vs heterosexual & 0.58 & $0.29-1.16$ & 0.125 \\
\hline MSM vs heterosexual & 0.96 & $0.56-1.63$ & 0.877 \\
\hline Other/unknown vs heterosexual & 1.18 & $0.70-1.99$ & 0.536 \\
\hline \multicolumn{4}{|l|}{ Ab-anti HCV } \\
\hline Positive vs negative & 1.50 & $0.91-2.48$ & 0.113 \\
\hline Unknown vs negative & 0.71 & $0.31-1.61$ & 0.413 \\
\hline Calendar year of ART initiation (per 3-years longer) & 1.30 & $1.14-1.49$ & $<0.0001$ \\
\hline CD4+ (per 100-cells/ $\mu$ L higher) ${ }^{a}$ & 0.91 & $0.84-0.99$ & 0.025 \\
\hline \multicolumn{4}{|l|}{ HIV-RNA ${ }^{a}$} \\
\hline$\geq 50$ vs $<50$ copies $/ \mathrm{ml}$ & 2.00 & $1.41-2.84$ & 0.0001 \\
\hline Triglycerides (per 50-mg/dl) ${ }^{a}$ & 1.07 & $1.05-1.09$ & $<0.0001$ \\
\hline Haemoglobin (per 5-g/dl higher) ${ }^{a}$ & 2.59 & $1.47-4.55$ & 0.001 \\
\hline Fasting glucose (per 10-mg/dL higher) ${ }^{a}$ & 1.17 & $1.15-1.20$ & $<0.0001$ \\
\hline Use of statins (yes vs no) ${ }^{a}$ & 1.21 & $0.71-2.07$ & 0.474 \\
\hline Ever use of lamivudine (yes vs no) & 0.71 & $0.36-1.40$ & 0.325 \\
\hline Ever use of abacavir (yes vs no) & 0.53 & $0.36-0.77$ & 0.0008 \\
\hline Ever use of emtricitabine (yes vs no) & 0.30 & $0.17-0.54$ & $<0.0001$ \\
\hline Ever use of tenofovir (yes vs no) & 0.48 & $0.29-0.81$ & 0.006 \\
\hline Ever use of stavudine (yes vs no) & 1.58 & $1.02-2.44$ & 0.042 \\
\hline Ever use of zidovudine (yes vs no) & 1.62 & $0.97-2.70$ & 0.067 \\
\hline Ever use of didanosine (yes vs no) & 0.98 & $0.66-1.46$ & 0.932 \\
\hline Ever use of efavirenz (yes vs no) & 0.66 & $0.45-0.97$ & 0.034 \\
\hline Ever use of nevirapine (yes vs no) & 0.36 & $0.23-0.56$ & $<0.0001$ \\
\hline Ever use of ritonavir (yes vs no) & 0.95 & $0.60-1.53$ & 0.845 \\
\hline Ever use of saquinavir (yes vs no) & 0.91 & $0.60-1.38$ & 0.643 \\
\hline Ever use of lopinavir (yes vs no) & 0.76 & $0.38-1.02$ & 0.064 \\
\hline Ever use of atazanavir (yes vs no) & 0.44 & $0.29-0.65$ & $<0.0001$ \\
\hline Ever use of darunavir (yes vs no) & 0.24 & $0.13-0.45$ & $<0.0001$ \\
\hline
\end{tabular}

Abbreviations: $A H R$ adjusted hazard ratio, $95 \% \mathrm{Cl}, 95 \%$ confidence interval of the hazard ratio

${ }^{\text {a }}$ Time-updated covariate

regular basis (glucose testing at least twice per year), which eliminates the possibility that we underestimated the incidence of DM. Second, our DM diagnoses were accurate, as each case was individually reviewed and confirmed to fulfil the American Diabetes Association criteria. Third, we included a large cohort of HIVinfected patients who had available data from a relatively long follow-up. 


\section{Conclusions}

In conclusion, a higher risk of DM was not associated with the use of statin but with previous use of stavudine, shorter ART duration, detectable HIV RNA levels, hypertriglyceridemia, hyperglycemia, higher hemoglobin levels, older age and obesity. In contrast, a lower risk of developing DM was associated with higher CD4+ cell counts and the use of emtricitabine, tenofovir, efavirenz, nevirapine, atazanavir and darunavir.

\section{Additional files}

Additional file 1: Figure S1. Flow-chat of patients' selection. (JPG $50 \mathrm{~kb}$ )

Additional file 2: Table S1. Exposure to antiretroviral drugs during

follow-up according to occurrence of type 2 diabetes. (DOCX $15 \mathrm{~kb}$ )

\section{Abbreviations}

AHR: Adjusted hazard ratio; ART: Antiretroviral therapy; BMI: Body mass index; Cl: Confidence interval; DM: Type 2 diabetes mellitus; HBV: Hepatitis B virus; HCV: Hepatitis C virus; HMG-CoA: 3-hydroxy-3-methylglutaryl-coenzymeA; HR: Hazard ratio; IDD-HSR: Infectious diseases Department database at the San Raffaele Hospital; IQR: Interquartile range; IVDU: Intravenous drug use; MSM: Men who have sex with men; NRTI: Nucleoside reverse transcriptase inhibitor; PI: Protease inhibitor; PYFU: Person-years of follow-up

\section{Acknowledgements}

We would like to thank Editage (https://www.editage.com/) for providing medical writing services on behalf of the San Raffaele Scientific Institute.

\section{Funding}

This study did not receive external funding.

\section{Availability of data and materials}

The datasets analysed during the current study are available from the corresponding author on reasonable request.

\section{Authors' contributions}

VS conceived the study, collected and reviewed the data, and wrote the first draft of the paper; LG performed the statistical analyses and wrote the first draft of the paper; AP collected the data and contributed to writing the paper; SS, NG and FC collected the data and contributed to writing the paper; CV and EC contributed to the management and supervision of data collection; PP collected and reviewed the data; AL collected the data and contributed to writing the paper; AC conceived the study, collected the data, and contributed to writing the paper. All of the authors have read and approved the final manuscript.

\section{Competing interests}

NG is a member of the editorial board of BMC Infectious Diseases.

\section{Consent for publication}

Not applicable.

\section{Ethics approval and consent to participate}

This retrospective observational study was approved by the ethics committee of the San Raffaele Scientific Institute; the patients provided written informed consent for scientific analysis of their clinical and laboratory data.

\section{Author details}

${ }^{1}$ Department of Infectious Diseases, San Raffaele Scientific Institute, via Stamira d'Ancona 20, 20127 Milan, Italy. ${ }^{2}$ Università Vita-Salute San Raffaele, Milan, Italy. ${ }^{3}$ Cardiometabolic and Clinical Trials Unit, Internal Medicine Department, Metabolic and Cardiovascular Division, San Raffaele Scientific Institute, Milan, Italy.
Received: 19 August 2016 Accepted: 8 December 2016

Published online: 07 January 2017

\section{References}

1. Aberg JA. Cardiovascular complications in HIV management: past, present, and future. J Acquir Immune Defic Syndr. 2009;50:54-64.

2. Freiberg MS, Chang CC, Kuller LH, Skanderson M, Lowy E, Kraemer KL, et al. HIV infection and the risk of acute myocardial infarction. JAMA Intern Med. 2013;173:614-22.

3. Sico JJ, Chang CC, So-Armah K, Justice AC, Hylek E, Skanderson M, et al. HIV status and the risk of ischemic stroke among men. Neurology. 2015;84: 1933-40.

4. European AIDS Clinical Society Guidelines; Version 8.1, October 2016. Available: http://www.eacsociety.org/files/guidelines_8.1-english_web.pdf.

5. Moore RD, Bartlett JG, Gallant JE. Association between use of HMG CoA reductase inhibitors and mortality in HIV-infected patients. PLoS One. 2011; 6:e21843.

6. Rasmussen LD, Kronborg G, Larsen CS, Pedersen C, Gerstorf J, Obel N. Statin therapy and mortality in HIV-infected individuals; a Danish nationwide population-based cohort study. PLoS One. 2013;8:e52828.

7. Overton ET, Kitch D, Benson CA, Hunt PW, Stein JH, Smurzynski M, et al. Effect of statin therapy in reducing the risk of serious non-AIDS defining events and nonaccidental deaths. Clin Infect Dis. 2013;56:1471-9.

8. Galli L, Spagnuolo V, Poli A, Salpietro S, Gianotti N, Cossarini F, et al. Use of statins and risk of AIDS-defining and non-AIDS-defining malignancies among HIV-1 infected patients on antiretroviral therapy. AIDS. 2014;28:2407-15.

9. Chao C, Xu L, Abrams DI, Towner WJ, Horberg MA, Leyden WA, et al. HMGCoA reductase inhibitors (statins) use and risk of non-Hodgkin lymphoma in HIV-positive persons. AIDS. 2011;25:1771-7.

10. Sattar N, Preiss D, Murray HM, Welsh P, Buckley BM, de Craen AJ, et al. Statins and risk of incident diabetes: a collaborative meta-analysis of randomized statin trials. Lancet. 2010;375:735-42.

11. Carter AA, Gomes T, Camacho X, Juurlink DN, Shah BR, Mamdani MM. Risk of incident diabetes among patients treated with statins: population based study. BMJ. 2013:346:f2610.

12. Seshasai SR, Welsh P, Murphy SA, Ho JE, Waters DD, DeMicco DA, et al. Risk of incident diabetes with intensive-dose compared with moderate-dose statin therapy. JAMA. 2011;305:2556-64.

13. Swerdlow DI, Preiss D, Kuchenbacecker KB, Holmes MV, Engmann JE, Shah T, et al. HMG-coenzyme A reductase inhibition, type 2 diabetes, and bodyweight: evidence from genetic analysis and randomised trials. Lancet. 2015;385:351-61.

14. Robinson JG. Statins and diabetes risk: how real is it and what are the mechanisms? Curr Opin Lipidol. 2015;26:228-35.

15. Galli L, Salpietro S, Pellicciotta G, Galliani A, Piatti P, Hasson H, et al. Risk of type 2 diabetes among HIV-infected and healthy subjects in Italy. Eur J Epidemiol. 2012;27:657-65.

16. Erlandson KM, Jiang Y, Debanne SM, McComsey GA. Rosuvastatin worsens insulin resistance in HIV-infected adults on antiretroviral therapy. Clin Infect Dis. 2015:61:1566-72.

17. Calza L, Colangeli V, Magistrelli E, Manfredi R, Bon I, Re MC et al. No correlation between statin exposure and incident diabetes mellitus in HIV-1infected patients receiving combination antiretroviral therapy. HIV Medicine. 2016. doi: 10.1111/hiv.12374

18. Lichtenstein KA, Hart RL, Wood KC, Bozzette S, Buchacz K, Brooks JT. HIV outpatient study investigators statin use is associated with incident diabetes mellitus among patients in the HIV outpatient study. J Acquir Immune Defic Syndr. 2015;69:306-11.

19. American Diabetes Association. Classification and diagnosis of diabetes mellitus. Diabetes Care. 2015;38(Supplement 1):S8-16.

20. Levesque LE, Hanley JA, Kezouh A, Suissa S. Problem of immortal time bias in cohort studies: example using statins for preventing progression of diabetes. BMJ. 2010;340:b5087.

21. Fine JP, Gray RJ. A proportional hazards model for the subdistribution of a competing risk. J Am Stat Assoc. 1999;94:496-509.

22. De Wit S, Sabin CA, Weber R, Worm SW, Reiss P, Cazanave C, et al. Incidence and risk factors for new-onset diabetes in HIV-infected patients. Diabetes Care. 2008:31:1224-9.

23. Betteridge J, Carmena R. The diabetogenic action of statins mechanisms and clinical implications. Nat Rev Endocrinol. 2015. doi:10.1038/nrendo.2015.194. 
24. Lederberger B, Furrer H, Rickenbach M, Lehmann R, Elzi L, Hirschel B, et al. Factors associated with the incidence of type 2 diabetes mellitus in HIV-infected participants in the Swiss HIV Cohort Study. Clin Infect Dis. 2007:45:111-9.

25. Brown TT, Cole SR, Li X, Kingsley LA, Palella FJ, Riddler SA, et al. Antiretroviral therapy and the prevalence of diabetes mellitus in Multicenter AIDS cohort study. Arch Inter Med. 2005;165:1179-84.

26. Capeau J, Bouteloup V, Katlama C, Bastard JP, Guiyedi V, Salmon-Ceron D, et al. Ten-year diabetes incidence in $1046 \mathrm{HIV}$-infected patients started on a combination antiretroviral treatment. AIDS. 2012;26:303-14.

27. Mehta SH, Moore RD, Thomas DL, Chaisson RE, Sulkowski MS. The effect of HAART and HCV infection on the development of hyperglycemia among HIV-infected persons. J Acquir Immune Defic Syndr. 2003:33:577-84

28. Samaras K. Prevalence and pathogenesis of diabetes mellitus in HIV-1 infection treated with combined antiretroviral therapy. J Acquir Immune Defic Syndr. 2009;50:499-505.

29. Brambilla AM, Novati R, Calori G, Meneghini E, Vacchini D, Luzi L, et al. Stavudine or indinavir-containing regimens are associated with an increased risk of diabetes mellitus in HIV-infected individuals. AIDS. 2003;17:1993-5.

30. Mulligan K, Tai VW, Algren H, Abrams DI, Leiser RJ, Lo JC, et al. Altered fat distribution in HIV-positive men on nucleoside analog reverse transcriptase inhibitor therapy. J Acquir Immune Defic Syndr. 2001;26:443-8.

31. Mallal SA, John M, Moore CB, James IR, McKinnon EJ. Contribution of nucleosides analogues reverse transcriptase inhibitors to subcutaneous fat wasting in patients with HIV infection. AIDS. 2000;14:1309-16.

32. Ballocca F, Gili S, D'Ascenzo F, Marra WG, Cannillo M, Calcagno A et al. HIV Infection and Primary Prevention of Cardiovascular Disease: Lights and Shadows in the HAART Era. Prog Cardiovasc Dis. 2016;58:565-76.

33. Randell PA, Jackson AG, Zhing L, Yale K, Moyle GJ. The effect of tenofovir diproxyl fumarate on whole-body insulin sensitivity, lipids and adipokines in healthy volunteers. Antivir Ther. 2010;15:227-33.

34. Shlay JC, Visnegarwala F, Bartsch G, Wang J, Peng G, El-Sadr WM, et al. Body composition and metabolic changes in antiretroviral-naïve patients randomized to didanosine and stavudine vs. abacavir and lamivudine. J Acquir Immune Defic Syndr. 2005;38:147-55.

35. Busti A, Bedimo R, Margolis DM, Hardin DS. Improvement in insulin sensitivity and dyslipidemia in protease inhibitors-treated adult male patients after switch to atazanavir/ritonavir. J Invest Med. 2008:56:539-44.

36. Capel E, Auclair M, Caron-Debarle M, Capeau J. Effects of ritonavir-boosted darunavir, atazanavir and lopinavir on adipose functions and insulin sensitivity in murine and human adipocytes. Antivir Ther. 2012;17:549-56.

37. Aberg JA, Tebas P, Overton ET, Gupta SK, Sax PE, Landay A, et al. Metabolic effects of darunavir/ritonavir versus atazanavir/ritonavir in treatment naïve, HIV type 1-infected subjects over 48 weeks. AIDS Res Hum Retroviruses. 2012;28:1184-95.

38. Tebas P, Yarasheski K, Henry K, Claxton S, Kane E, Bordenave B, et al. Evaluation of the virological and metabolic effects of switching protease inhibitor combination antiretroviral therapy to nevirapine-based therapy for the treatment of HIV infection. AIDS Res Hum Retroviruses. 2004;20:589-94.

\section{Submit your next manuscript to BioMed Central and we will help you at every step:}

- We accept pre-submission inquiries

- Our selector tool helps you to find the most relevant journal

- We provide round the clock customer support

- Convenient online submission

- Thorough peer review

- Inclusion in PubMed and all major indexing services

- Maximum visibility for your research

Submit your manuscript at www.biomedcentral.com/submit
( BioMed Central 